\section{Probing the sea}

\section{Molecular Approaches to the Study} of the Ocean

edited by Keith E. Cooksey

Chapman and Hall: 1998. Pp. 549. £110, $\$ 199.95$

\section{N.G.Carr}

About 20 years ago, some biological oceanographers, not least the late Ian Morris, began to argue that the application of molecular biology to the study of oceanic phytoplankton would be the next impetus to move the subject along, following the success of chemical and physical techniques such as radioactive isotope flow and fluorescence analysis. The recognition around that time of the microbial loop, in which a large proportion of photosynthetic productivity is recycled at the bacterial and protist level, would have encouraged such optimism.

Compared with clinical research, for example, oceanographic applications were rather slow in being optimized, but the use of molecular biology is at last changing our understanding of ocean microbiology in terms of what is there and what it does. The Molecular Ecology of Aquatic Microbes (Springer, 1995) was the first collection of articles on the subject, but Molecular Approaches to the Study of the Ocean also emphasizes subjects usually associated with aspects of marine biology such as toxins and adhesive proteins. It is a moot point whether the benefits of its broad coverage compensate for a degree of loss of focus .

The development of a molecular phylogeny based on 16S RNA gene sequence has revolutionized ideas of bacterial relatedness and allowed the first rational understanding of bacterial evolution. An excellent chapter by DeLong discusses the application of molecular phylogenetics to marine microorganisms including protists and some metazoans. A valuable part of this is a comparison of some of the methods of handling the sequence data that lead to the now familiar unrooted tree expression of relatedness. This approach has produced an analysis of the bacterial community structure within the open ocean. The myriad organisms seen microscopically and largely unidentified can now be related to the known microbial world. An important outcome of this work, which has relevance to microbiology as a whole, has been the discovery that the Archaea appear to be widespread in the ocean and not, as previously thought, confined to extreme environments.

One of the difficulties of working with, and writing about, marine bacteria and phytoplankton is relating their microbiological interest to their contribution to the understanding of the overall process of biological oceanography. In a long chapter with the deceptively simple title of "Molecular approaches to microbial biomass estimation", Karl and Dobbs achieve this splendidly. They combine details of how the current experimental strategies have evolved with a feel for the sheer scale of the microbially driven biogeochemical cycles in what they describe as the largest contiguous habitat on Earth.

The feature of molecular biology that makes it so effective in unravelling biological oceanography is the specificity that derives from nucleic-acid sequence probes and immunological recognition of proteins. The article by Zehr and Hiorns exemplifies this and builds on successful applications for measuring aspects of bacterial nutrition and rates of phytoplankton photosynthesis to suggest a wide range of cellular activities open to molecular examination and of use in determining the metabolic status of different components of microbial populations.

The book has 27 chapters, so perhaps it is not surprising that several describe fields of study showing modest progress and that one or two are made up largely of previously published material. For the most part though, the book comprises relevant, well-written accounts that cover the molecular analysis and ecology of the oceans. Other advanced techniques, such as flow cytometry and developments in fluorescence analysis, are discussed in a way that indicates that the authors and editor appreciate that progress will usually involve the integration of disciplines.

Most researchers in biological oceanography will find things of value in this wellproduced book, and some of the chapters provide for a wider readership an excellent introduction to this critical area of environmental biology.

N. G. Carr is in the Department of Biological

Sciences, University of Warwick, Coventry CV4 $7 A L, U K$.

\section{Patchy coverage}

\section{Climate Process and Change}

by Edward Bryant

Cambridge University Press: 1997. Pp. 209.

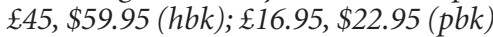

\section{Thomas F Stocker}

The science of Earth's climate system has gone from being the preoccupation of a handful of pioneers to a large international research effort. Its unique complexity means that only the combination of high-quality research across disciplinary boundaries will generate the innovative results needed for progress. So a book intended for use in undergraduate courses is timely.

In Climate Process and Change, Edward Bryant seeks to present in simple terms the workings of the climate system and its changes. He does so in three parts, on processes, change and impact, in just over 200 pages, too few for in-depth discussion. Readers would appreciate references to more specialized sources or excellent textbooks such as Physics of Climate by J. P. Peixoto and A. H. Oort (American Institute of Physics, 1992) or Paleoclimatology by T. J. Crowley and G. R. North (Oxford University Press, 1991).

More than half the book focuses on the past century, and the question of global warming is a recurring theme, presented here in a rather one-sided manner. Students reading this text would end up with the "acquired bias from previous instruction" that Bryant sets out to correct.

Central to our understanding of climate processes are the natural sciences, whose language is equations. This book contains very little — and often sloppy — physics, and the few equations are hardly useful; for example, $y=b x^{n}$ (where $\left.n \neq 1\right)$ is explained by "Many climatic processes behave like this and have a value of $n$ between 1.0 and 2.0".

A chapter on the transport of heat and matter introduces the reader to large-scale meridional air flow - the concept of transient eddies is not mentioned - and to urban climate and "mobile polar highs". We learn that this concept, unknown to dynamical meteorologists, explains the atmospheric circulation for the climatic states of the glacial, today and in the future. A narrow and often incorrect view of ocean circulation and processes follows.

In the discussion of Pleistocene change, there is no metion of the rapidly accumulating results from various novel proxy indicators extracted from marine sediments, corals and tree rings. There is a fairly complete account of the causes of climate change but stating that it is impossible to attribute temperature change during the past century to different causes ignores recent promising advances in statistical analysis.

The book closes with two interesting chapters on the impact of climate change on health and ecosystems. I am happy to learn that climate-related diseases "may not be the biggest threat to human health" and that food contamination at a "fast-food outlet or wedding reception" may be more dangerous.

In his epilogue Bryant says that "if greenhouse warming is a reality, then its arrival may well be timely, because it has the potential to compensate for the strong cooling that may be a natural part of the ocean-atmosphere system, under the heavy atmospheric dust and sulphate aerosol loadings presently being stimulated by human activity". I prefer his alternative view, earlier in the book: "as with all human tampering with climate, there are bound to be negative ramifications".

Thomas F. Stocker is in the Division of Climate and Environmental Physics, Physics Institute,

University of Bern, 3012 Bern, Switzerland. 